Cite this: Phys. Chem. Chem. Phys., 2014, 16, 7491

Received 22nd January 2014, Accepted 3rd March 2014

DOI: $10.1039 / c 4 c p 00338 a$

www.rsc.org/pccp

\section{An inelastic neutron scattering study of dietary phenolic acids}

\author{
M. Paula M. Marques, ${ }^{\text {ab }}$ Luís A. E. Batista de Carvalho, ${ }^{a}$ Rosendo Valero, ${ }^{a}$ \\ Nelson F. L. Machado ${ }^{a}$ and Stewart F. Parker ${ }^{C}$
}

\begin{abstract}
The conformational preferences and hydrogen-bonding motifs of several potential chemopreventive hydroxycinnamic derivatives were determined by inelastic neutron scattering spectroscopy. The aim is to understand their recognized beneficial activity and establish reliable structure-activity relationships for these types of dietary phytochemicals. A series of phenolic acids with different hydroxyl/methoxyl ring substitution patterns were studied: trans-cinnamic, $p$-coumaric, $m$-coumaric, trans-caffeic and ferulic acids. Their INS spectra were completely assigned by theoretical calculations performed at the Density Functional Theory level, for the isolated molecule, dimeric centrosymmetric species and the solid (using plane-wave expansion approaches). Access to the low energy vibrational region of the spectra enabled the identification of particular modes associated with intermolecular hydrogen-bonding interactions, which are the determinants of the main conformational preferences and antioxidant capacity of these systems.
\end{abstract}

\section{Introduction}

Phenolic acid derivatives constitute some of the most ubiquitous groups of plant metabolites present in the human diet in significant amounts, which have long been known to display antioxidant properties, in particular due to the availability of phenolic hydrogens that allow them to act as H-donating radical scavengers. It is generally assumed that this radical scavenging capacity is closely related to the compounds' hydrogen or electron donating ability, as well as to the stability of the resulting phenoxyl radicals. Since oxidative damage caused by reactive oxidant species to vital biomolecules, such as DNA, lipids and proteins, is responsible for numerous pathological processes including inflammation, atherosclerosis, cancer and neurodegenerative disorders, ${ }^{1-4}$ these compounds have lately been the subject of intense research in health sciences., ${ }^{1,3,5-11}$ While extensively used as antioxidant additives in both the food and pharmaceutical industries, ${ }^{12}$ these types of molecules display a large variety of biological functions, from anti-inflammatory and antimutagenic to antitumoral and carcinogenesis modulation activities, ${ }^{2,13}$ due to their ability to inhibit deleterious oxidative processes. In particular, cinnamic acid and its derivatives (e.g. caffeic acid phenethyl ester $(\mathrm{CAPE})^{\mathbf{1 4}}$ ) are known to display

\footnotetext{
${ }^{a}$ Research Unit “Molecular Physical Chemistry”, Faculty of Science and Technology, University of Coimbra, 3004-535 Coimbra, Portugal

${ }^{b}$ Department of Life Sciences, Faculty of Science and Technology, University of Coimbra, 3001-401, Coimbra, Portugal. E-mail: pmc@ci.uc.pt

${ }^{c}$ ISIS Facility, SFTC Rutherford Appleton Laboratory, Chilton, Didcot, OX110QX, UK
}

interesting antioxidant and selective antitumor properties, ${ }^{1,3,6,9,15-18}$ and are widely distributed in plant tissues, thus being regularly consumed in the daily diet. ${ }^{19,20}$ Ferulic acid, for instance, a methoxycontaining hydroxycinnamic acid, is abundant in plant cell wall components (e.g. cereals and seeds of coffee, apple, orange and peanut). Plant-derived polyphenolic compounds (phenolic acids, esters or amides) are therefore promising candidates as preventive agents against oxidative stress-induced diseases, apart from being widely exploited as model systems for drug development. The evaluation of the antioxidant properties of phenolic derivatives of natural or synthetic origin, aiming at the prediction of their biochemical and pharmacological activity, is nowadays a key area of research in medicinal chemistry.

The prospective health benefits arising from the antioxidant capacity of phenolic derivatives are governed by strict structureactivity relationships (SARs), namely the number and relative position of the ring hydroxyl substituents, or the chemical nature and spatial orientation of the linker between the ring and the carboxylate/ester moiety. These, apart from determining their biological action, modulate their lipophilicity, systemic distribution and bioavailability in the sites of oxidation within the cell. Also, conformational preferences such as flexibility, formation of hydrogen bonds - either intra- or intermolecular - and planar or skewed relative orientations of the substituent groups in the aromatic ring determine the biological properties of the systems. For these polyphenolic molecules, the conformational preferences and relative stability are mostly determined by an extensive $\pi$-electron delocalization, as well as by the formation of medium to strong $(\mathrm{O}) \mathrm{H} \cdots \mathrm{O}$ and/or $(\mathrm{C}) \mathrm{H} \cdots \mathrm{O}$ intra- and intermolecular hydrogen bonds, which have long been known to be 
relevant for the stability and function of numerous systems. These close contacts also account for the formation of phenolic dimeric species, shown to occur both in the solid state and in solution for these types of compounds. ${ }^{21,22}$

An accurate conformational analysis of this class of molecules is therefore essential in order to clearly understand their mode of action and to establish reliable SARs, which is an essential step in the rational design of new phenolic-based chemopreventive/ therapeutic agents, coupling an optimized (and perhaps selective) efficacy to a minimal toxicity. Such a goal can be attained through the combined use of spectroscopic techniques (e.g. vibrational spectroscopy) and theoretical approaches, in order to determine the compounds' most stable geometries, as well as their main conformational preferences and possible interactions with biological targets and receptors.

Inelastic Neutron Scattering (INS) spectroscopy is a technique that is well suited to the study of hydrogenous compounds such as phenolic systems. The neutron scattering cross-section of an element $(\sigma)$ is characteristic of that atom and independent of its chemical environment. Since the value for hydrogen (80 barns) far exceeds that of all other elements (typically ca. 5 barns), the modes of significant hydrogen displacement $\left(u_{i}\right)$ dominate the INS spectra. For a mode at a given energy $\nu_{i}$, the intensity of a powdered sample obeys the simplified relationship,

$$
S_{i}^{\bullet}\left(Q^{2}, \nu_{i}\right)=\frac{\left(Q^{2} u_{i}^{2}\right) \sigma}{3} \exp \left(-\frac{Q^{2} \alpha_{i}^{2}}{3}\right)
$$

where $Q\left(\AA^{-1}\right)$ is the momentum transferred from the neutron to the sample and $\alpha_{i}(\AA)$ is related to a weighted sum of all the displacements of the atom. Thus, not only the energies of the vibrational transitions (the eigenvalues, $\nu_{i}$ ) but also the atomic displacements (the eigenvectors, $u_{i}$ ) are available from experimental observation. This significantly enhances the information obtainable from the vibrational spectrum and adds to that from the complementary Raman and infrared vibrational spectroscopic methods. Additionally, the absence of selection rules and ready access to the region below $400 \mathrm{~cm}^{-1}$ enable the detection of some low frequency modes unavailable to these optical techniques. Since the spectral intensities can be quantitatively compared with those calculated by theoretical methods, by combining the INS results with quantum mechanical calculations it is possible to link molecular geometry with the experimental spectroscopic features and produce a consistent conformation for the systems under investigation.

Furthermore, since vibrational INS intensities are strongly dependent upon the motions of hydrogens, INS spectroscopy displays a unique sensitivity to hydrogen interactions, being an excellent technique for studying $\mathrm{H}$-bonding properties in

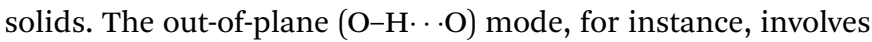
almost exclusively the motion of the hydrogen atom relative to the undeformed molecule, thus being easily identified by INS. Additionally, unlike optical methods such as Fourier transform infrared (FTIR) or Raman spectroscopies, INS is known to yield intense features in the low wavenumber region of the spectrum, where intermolecular vibrations associated with hydrogen-bonding mostly occur. Nevertheless, to date very few studies have been reported to probe the low-energy vibrational modes of phenolic systems, no INS data being found in the literature on this subject to the best of the authors' knowledge. A terahertz timedomain (THz-TD) analysis was performed for some hydroxycinnamic acids (including caffeic and ferulic acids) aimed at the detection and assignment of their low-frequency oscillators, in the solid state. ${ }^{23}$

The present work applies INS spectroscopy, coupled with Density Functional Theory (DFT)/Plane-wave (PW) calculations, to the study of a series of phenolic acids with different hydroxyl substitution patterns: trans-cinnamic (3-(phenyl)-2-propenoic, Cin), p-coumaric (3-(4-hydroxyphenyl)-2-propenoic or 3-hydroxycinnamic, $p$-C), m-coumaric (3-(3-hydroxyphenyl)-2-propenoic or 4-hydroxycinnamic, $m$-C), trans-caffeic (trans-3-(3,4-dihydroxyphenyl)-2propenoic, CA) and ferulic (trans-3-(4-hydroxy-3-methoxyphenyl)2-propenoic, FA) acids (Fig. 1). These are structurally different regarding the number and localization of the hydroxyl (or methoxyl) ring substituent groups. Their main conformational characteristics were previously determined by Raman spectroscopy, combined with DFT calculations, for the isolated molecule, their dimeric species and the solution species. ${ }^{3,6,9,16,21,24-28}$ Particular emphasis is given to the investigation of the hydrogenbonding profile of this kind of systems, aiming at a better understanding and prediction of their antioxidant activity. Location of low-frequency modes due to H-bonding is envisaged, namely the $(\mathrm{O} \cdots \mathrm{H})$ stretching. To this aim, deuteration of some of the compounds was carried out at specific sites (e.g. the carboxylic acid group), in order to better assign the oscillators
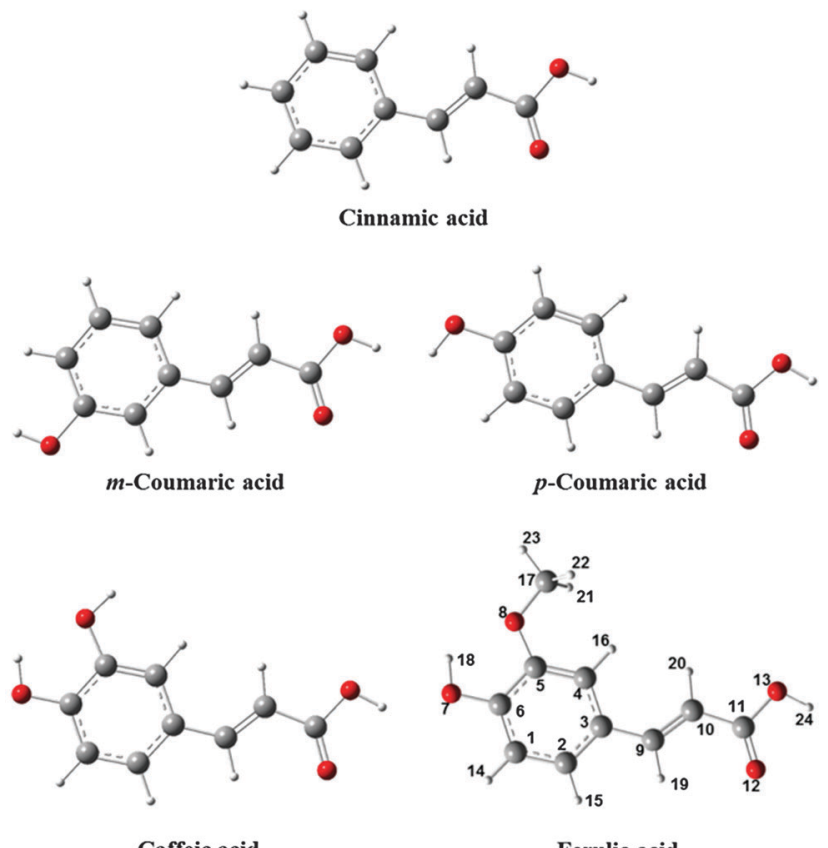

Caffeic acid

Ferulic acid

$$
\text { C } \bigcirc, \mathrm{OH}
$$

Fig. 1 Schematic representation of the most stable calculated gas-phase conformers (B3LYP/6-31G**) for the phenolic acids studied here. (The atom numbering is included.) 
involved in hydrogen interactions by comparison with the undeuterated samples.

In the analysis of the data particular attention was paid to the low wavenumber region of the spectra, where the most relevant changes are expected to occur. The theoretical INS transition intensities were obtained from the calculated normal mode eigenvectors, and the corresponding spectra were simulated using the aCLIMAX program. ${ }^{29}$ Thus, the combined INS and DFT data for both the condensed state and the isolated molecules allow us to assign the spectral changes due to both intra- and intermolecular $\mathrm{H}$-bonds, and to detect the characteristic $(\mathrm{O}-\mathrm{H} \cdots \mathrm{O})$ modes. This constitutes preliminary work for a future study of the dynamics of the proton transfer along hydrogen bonds within this type of phenolic system, which is of utmost relevance for numerous chemical and biochemical processes. $^{30}$

\section{Experimental}

\section{A. Reagents}

trans-Cinnamic, $p$-coumaric, $m$-coumaric, caffeic and ferulic acids (p.a. grade) were purchased from Sigma-Aldrich Química S.A. (Sintra, Portugal).

O-deuterated ferulic acid (at the carboxylic moiety) was prepared by solubilizing the solid compound in $\mathrm{D}_{2} \mathrm{O}$ ( $\mathrm{ca} .10 \%$ excess) and evaporating to dryness under vacuum (this process being repeated three times).

\section{B. INS spectroscopy}

The INS spectra were obtained at the ISIS Pulsed Neutron and Muon Source of the Rutherford Appleton Laboratory

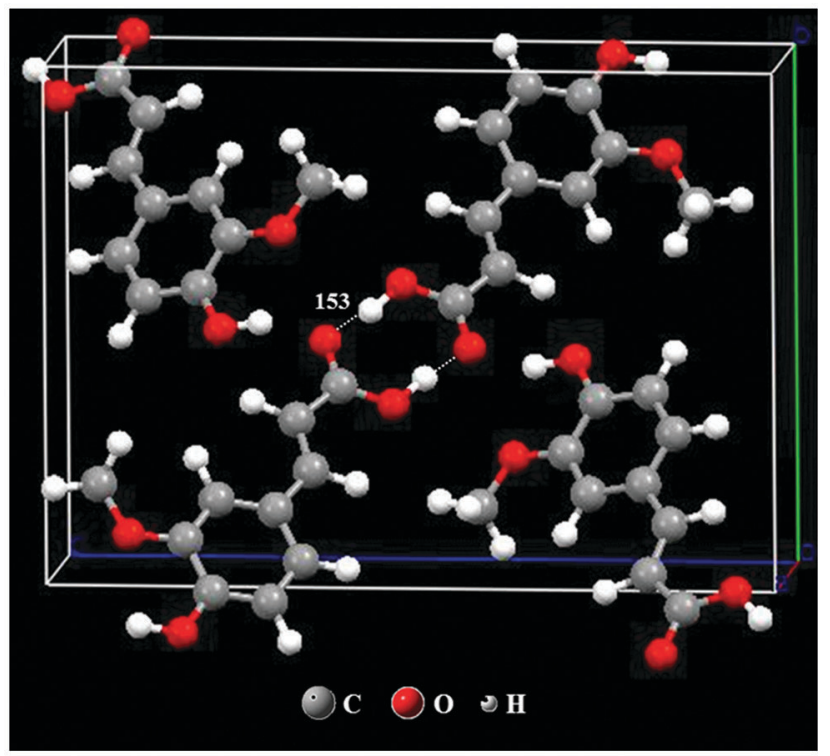

Fig. 2 Optimized solid-state structure of anhydrous ferulic acid (at the PBE/PWSCF level). Longitudinal view, along the a axis, showing the crystalline lattice arrangement including the unit cell. (Based on the published crystal structures. ${ }^{48}$ The dashed lines represent intermolecular $\mathrm{H}$-bonds (distances in pm).)

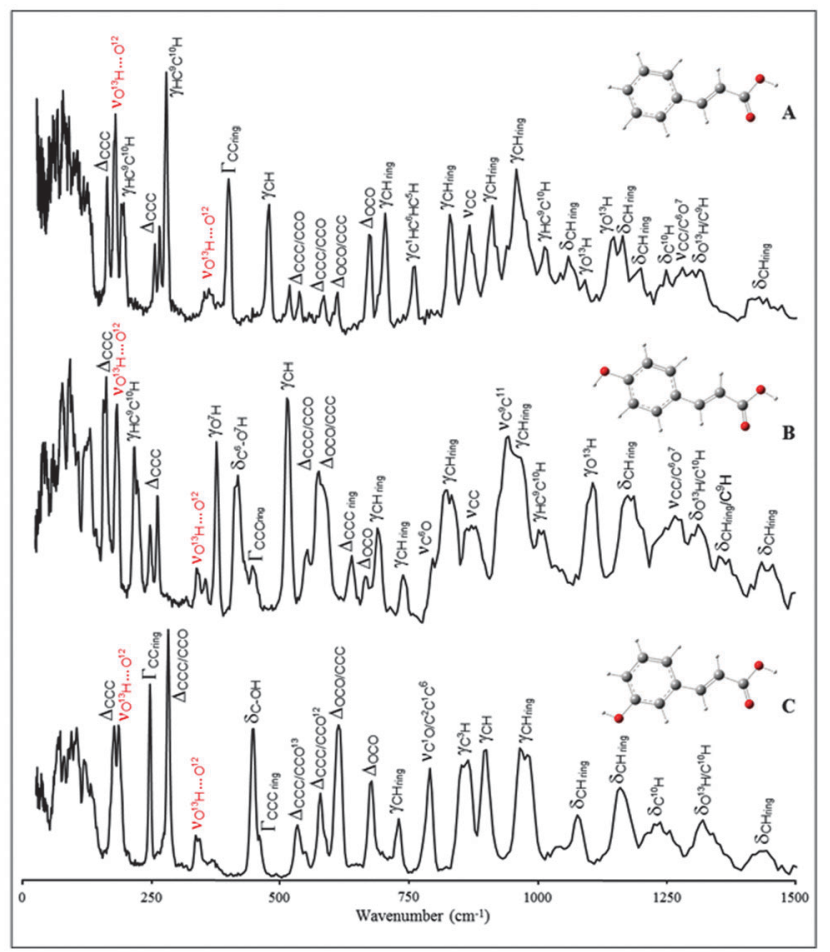

Fig. 3 Experimental INS spectra $\left(30-1500 \mathrm{~cm}^{-1}\right.$ ) for cinnamic (A), $p$-coumaric (B) and $m$-coumaric (C) acids. (The atoms are numbered according to Fig. 1.)

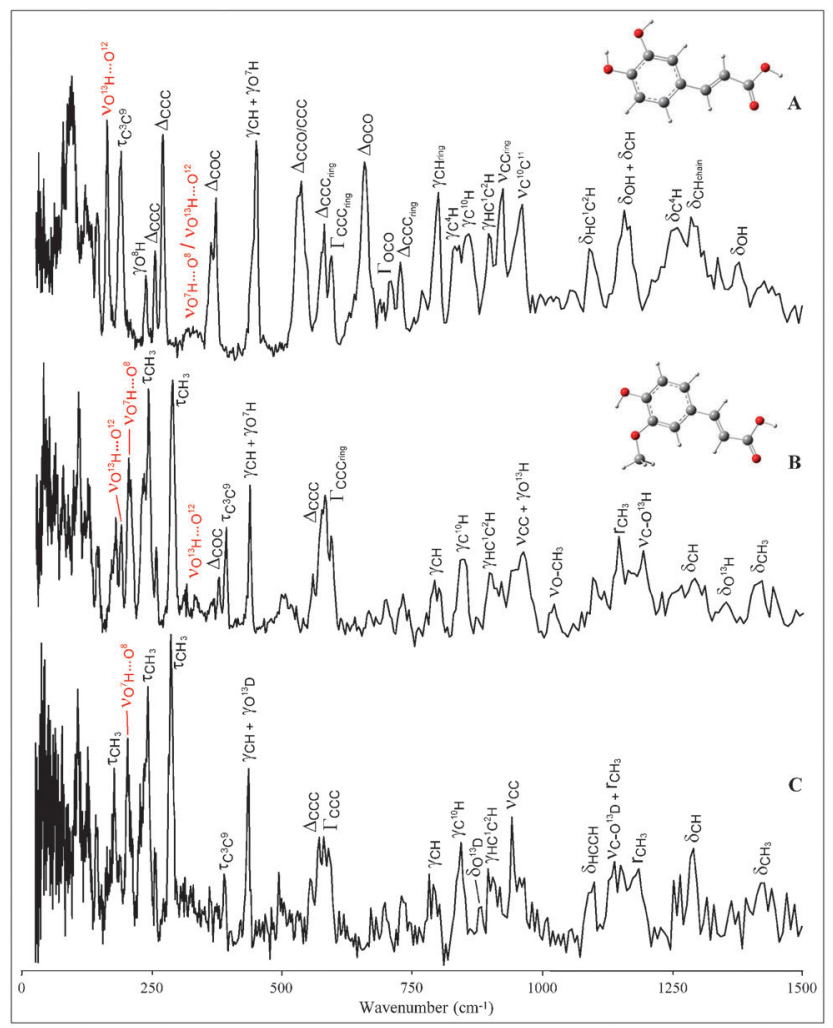

Fig. 4 Experimental INS spectra $\left(30-1500 \mathrm{~cm}^{-1}\right)$ for caffeic (A), ferulic (B) and $\mathrm{O}^{13}$-deuterated ferulic (C) acids. (The atoms are numbered according to Fig. 1.) 
(United Kingdom), on the TOSCA spectrometer. This is an indirect geometry time-of-flight, high resolution $((\Delta E / E) c a .1 .25 \%)$, broad range spectrometer. ${ }^{31}$ The samples (2-3 g) were wrapped in $4 \times 4 \mathrm{~cm}$ aluminium foil sachets, which filled the beam, and placed in thin walled aluminium cans. To reduce the impact of the Debye-Waller factor (the exponential term in eqn (1)) on the observed spectral intensity, the samples were cooled to $c a .10 \mathrm{~K}$. Data were recorded in the energy range -24 to $4000 \mathrm{~cm}^{-1}$ and converted to the conventional scattering law, $S(Q, \nu) v s$. energy transfer (in $\mathrm{cm}^{-1}$ ) through standard programs.

\section{C. Quantum mechanical calculations}

The quantum mechanical calculations were performed using the GAUSSIAN 03W program ${ }^{32}$ (G03W) within the Density Functional Theory (DFT) approach, in order to properly account for the electron correlation effects (particularly important in this kind of conjugated systems). The widely employed hybrid method denoted by B3LYP, which includes a mixture of HF and DFT exchange terms and the gradient-corrected correlation functional of Lee, Yang and Parr, ${ }^{33,34}$ as proposed and parameterized by Becke, ${ }^{35,36}$ was used, along with the double-zeta split valence basis set $6-31 \mathrm{G}^{* *} \cdot{ }^{37}$ Molecular geometries were fully optimised by the Berny algorithm, using redundant internal coordinates: ${ }^{38}$ the bond lengths to within $c a .0 .1 \mathrm{pm}$ and the bond angles to within $c a .0 .1^{\circ}$. The final root-mean-square (rms) gradients were always less than $3 \times 10^{-4}$ hartree bohr ${ }^{-1}$ or hartree radian $^{-1}$. No geometrical constraints were imposed on the molecules under study. The basis set superposition error (BSSE) correction for the dimerization energies was estimated by counterpoise (CP) calculations.

Natural bond orbital (NBO) analyses, ${ }^{39-41}$ as implemented in G03W, ${ }^{42}$ were carried out for the optimised geometries aiming at obtaining information on the nature of the interactions that determine conformer stability. Special attention was given to the Wiberg bond orders and energetics of the main interactions between "filled" (donor) Lewis-type NBOs and "empty" (acceptor)

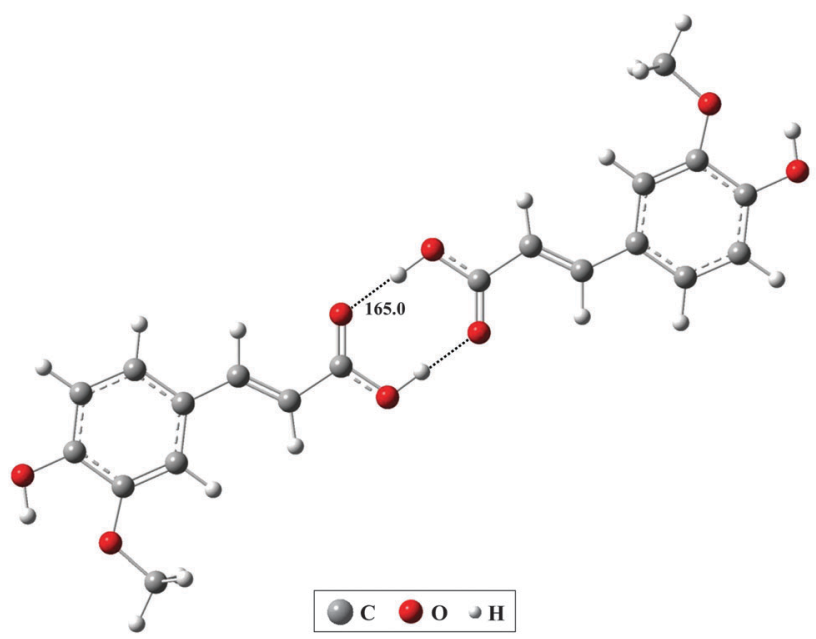

Fig. 5 Schematic representation of the most stable calculated structure (B3LYP/6-31G**) for the centrosymmetric top-to-top dimer of ferulic acid. (Distances are represented in pm.)
non-Lewis NBOs, evaluated by means of the 2nd-order perturbation theory (2nd-order stabilisation energies).

Calculations of the vibrational spectra were based on the optimised geometries. The harmonic vibrational wavenumbers, as well as their Raman activities and IR intensities, were

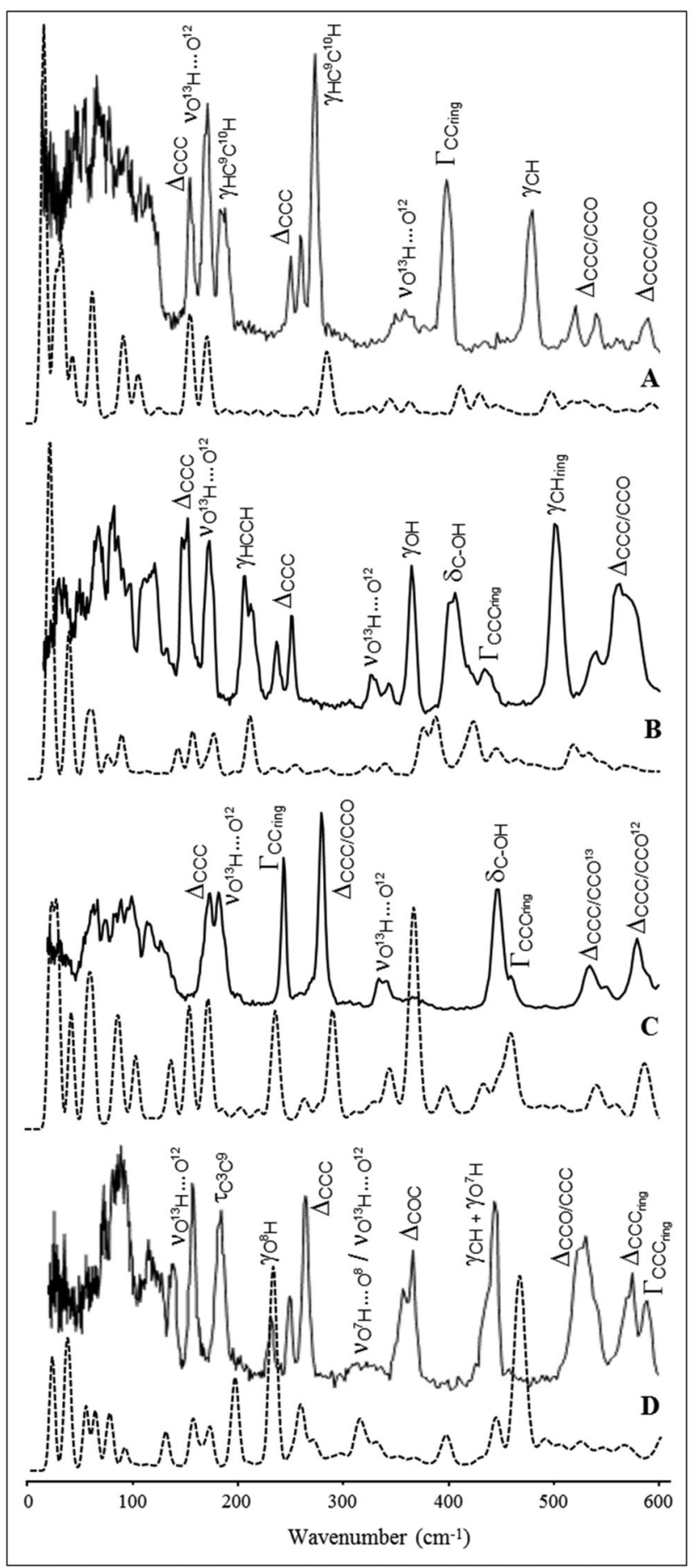

Fig. 6 INS spectra $\left(0-600 \mathrm{~cm}^{-1}\right)$ for cinnamic (A), p-coumaric (B), $m$-coumaric (C) and caffeic (D) acids: experimental - solid lines; calculated at the B3LYP/6-31G** level, for the top-to-top centrosymmetric dimer - dotted lines. (The atoms are numbered according to Fig. 1.) 
Table 1 Main experimental and calculated INS wavenumbers $\left(\mathrm{cm}^{-1}\right)$ for caffeic and ferulic acids

\begin{tabular}{|c|c|c|c|c|c|c|c|c|c|c|}
\hline \multicolumn{3}{|l|}{ CA } & \multicolumn{4}{|l|}{$\underline{\mathrm{FA}}$} & \multicolumn{3}{|l|}{$\underline{\text { FA deut }^{a}}$} & \multirow[b]{2}{*}{ Approximate description $^{b}$} \\
\hline $\operatorname{Exp}^{c}$ & $\begin{array}{l}\text { Calc/ } \\
\text { mon }^{d}\end{array}$ & $\begin{array}{l}\text { Calc/ } \\
\operatorname{dim}^{e}\end{array}$ & $\operatorname{Exp}^{c}$ & $\begin{array}{l}\text { Calc/ } \\
\text { mon }^{d}\end{array}$ & $\begin{array}{l}\text { Calc/ } \\
\operatorname{dim}^{e}\end{array}$ & Calc/PW ${ }^{f}$ & Exp & $\begin{array}{l}\text { Calc/ } \\
\text { mon }^{d}\end{array}$ & Calc/PW ${ }^{f}$ & \\
\hline & & & & & 3025 & $2602-2641$ & & 2208 & $1892-1918$ & $\nu\left(\mathrm{O}^{13} \mathrm{H}\right) ; \nu\left(\mathrm{O}^{13} \mathrm{D}\right)$ \\
\hline & & & & & 2926 & $2488-2489$ & & 2151 & $1867-1869$ & $\nu\left(\mathrm{O}^{13} \mathrm{H}\right) ; \nu\left(\mathrm{O}^{13} \mathrm{D}\right)$ \\
\hline$(1640)$ & 1741 & 1702 & 1698 & 1742 & 1701 & $1614-1623$ & $\sim 1694$ & 1734 & & $\nu(\mathrm{C}=\mathrm{O})$ \\
\hline \multirow[t]{2}{*}{$(1614)$} & 1624 & 1626 & $(1628)$ & 1630 & 1629 & $1612-1614$ & & & $1609-1616$ & $\nu\left(\mathrm{C}^{9}=\mathrm{C}^{10}\right)+(\mathrm{C}=\mathrm{C})_{\text {ring }}$ \\
\hline & & & $(1601)$ & 1595 & 1596 & $1582-1587$ & & & $1581-1590$ & $\nu(\mathrm{C}=\mathrm{C})_{\text {ring }}+\nu\left(\mathrm{C}^{9}=\mathrm{C}^{10}\right)$ \\
\hline $1575(1570)$ & 1598 & 1587 & & & & & & & & $\nu(\mathrm{C}=\mathrm{C})_{\text {ring }}$ \\
\hline \multirow[t]{2}{*}{1433} & 1426 & 1428 & 1448 & 1446 & 1446 & $1451-1456$ & 1447 & 1446 & $1447-1453$ & $\begin{array}{l}\delta_{\mathrm{a}}\left(\mathrm{CH}_{3}\right) \\
\delta\left(\mathrm{O}^{13} \mathrm{H}\right)\end{array}$ \\
\hline & & & $1417(1421)$ & 1421 & 1420 & $1413-1416$ & 1430 & 1421 & $1415-1417$ & $\delta_{\mathrm{s}}\left(\mathrm{CH}_{3}\right)$ \\
\hline $1382(1388)$ & 1383 & 1375 & 1356 (1371) & 1381 & 1376 & $1377-1380$ & & & & $\delta\left(\mathrm{O}^{7} \mathrm{H}\right)+\delta\left(\mathrm{O}^{13} \mathrm{H}\right)+\nu(\mathrm{CC})_{\text {ring }}$ \\
\hline $1344(1353)$ & 1358 & 1374 & & & & & & & & $\delta\left(\mathrm{O}^{7} \mathrm{H}\right)+\delta\left(\mathrm{O}^{13} \mathrm{H}\right) \nu(\mathrm{CC})_{\text {ring }}$ \\
\hline 1296 (1298) & 1298 & 1293 & 1296 & 1304 & 1300 & $1295-1302$ & 1295 & 1303 & $1296-1298$ & $\delta(\mathrm{CH})_{\text {chain }}$ \\
\hline $1262(1265)$ & 1248 & 1244 & 1263 & 1266 & 1264 & $1256-1262$ & 1260 & 1264 & $1258-1268$ & $\delta\left(\mathrm{C}^{4} \mathrm{H}\right)$ \\
\hline \multirow[t]{3}{*}{$1217(1220)$} & 1225 & 1243 & & & & & & & & $\delta(\mathrm{CH})$ \\
\hline & & & 1197 (1194) & 1191 & 1199 & $1184-1187$ & & & & $\begin{array}{l}\nu\left(\mathrm{C}-\mathrm{O}^{13} \mathrm{H}\right)+\delta\left(\mathrm{O}^{7} \mathrm{H}\right)+ \\
\delta(\mathrm{CH})_{\text {chain }}\end{array}$ \\
\hline & 1172 & 1174 & & & & & 1191 & 1192 & $1178-1188$ & $\begin{array}{l}r\left(\mathrm{CH}_{3}\right) \\
\delta\left(\mathrm{O}^{7} \mathrm{H}\right)+\delta(\mathrm{CH})\end{array}$ \\
\hline \multirow[t]{3}{*}{1162} & 1149 & 1148 & 1151 & 1147 & 1146 & $1147-1157$ & 1160 & 1169 & $1157-1171$ & $\begin{array}{l}\delta\left(\mathrm{O}^{7} \mathrm{H}\right)+\delta\left(\mathrm{O}^{8} \mathrm{H}\right)+\delta(\mathrm{CH}) \\
r\left(\mathrm{CH}_{3}\right)\end{array}$ \\
\hline & & & & & & & 1142 & 1147 & 1154-1155 & $\nu\left(\mathrm{C}-\mathrm{O}^{13} \mathrm{D}\right)+r\left(\mathrm{CH}_{3}\right)$ \\
\hline & & & & & & & & 1135 & $1135-1146$ & $r\left(\mathrm{CH}_{3}\right)$ \\
\hline \multirow[t]{2}{*}{1098} & 1096 & 1094 & $1104(1118)$ & 1105 & 1107 & 1101-1109 & 1101 & 1108 & $1093-1110$ & $\delta\left(\mathrm{HC}^{1} \mathrm{C}^{2} \mathrm{H}\right)$ \\
\hline & & & 1025 & 1029 & 1029 & $1019-1020$ & & & & $\nu\left(\mathrm{O}-\left(\mathrm{CH}_{3}\right)\right) \nu(\mathrm{CC})_{\text {ring }}$ \\
\hline 964 & 989 & 966 & 966 & & 966 & $960-966$ & 966 & & & $\nu \mathrm{C}^{10} \mathrm{C}^{11}$ \\
\hline 927 & 954 & 945 & $\sim 948$ & 952 & 946 & $950-953$ & 947 & 940 & $931-933$ & $\nu(\mathrm{CC})_{\text {ring }}+\gamma\left(\mathrm{O}^{13} \mathrm{H}\right)$ \\
\hline \multirow[t]{2}{*}{904} & 907 & 908 & 903 & 908 & 907 & $904-909$ & 908 & 908 & $904-909$ & $\gamma\left(\mathrm{HC}^{1} \mathrm{C}^{2} \mathrm{H}\right)_{\mathrm{op}}$ \\
\hline & & & & & & & 887 & 883 & $762-765$ & $\delta\left(\mathrm{O}^{13} \mathrm{D}\right) \nu\left(\mathrm{C}^{10} \mathrm{C}^{11}\right)$ \\
\hline 861 & 866 & 849 & $850(867)$ & 844 & 848 & $853-854$ & 848 & 844 & $837-833$ & $\gamma\left(\mathrm{C}^{10} \mathrm{H}\right)$ \\
\hline 840 & 848 & 814 & & 828 & 827 & $836-837$ & & & & $\gamma\left(\mathrm{C}^{4} \mathrm{H}\right)$ \\
\hline $802(802)$ & 795 & 798 & 805 & & 801 & $789-794$ & 808 & 800 & $789-797$ & $\gamma(\mathrm{CH})_{\text {ring }}$ \\
\hline 775 & & 788 & 794 & 798 & 799 & $807-808$ & 798 & 797 & $806-807$ & $\Delta(\mathrm{CCC})_{\mathrm{ring}}$ \\
\hline 731 & & 751 & 735 & 732 & 736 & $746-754$ & 737 & 728 & $730-738$ & $\Delta(\mathrm{CCC})_{\mathrm{rin} \gamma}$ \\
\hline 712 & & 712 & 702 & 723 & 713 & $700-702$ & 708 & 715 & $695-702$ & $\Gamma\left(\mathrm{O}^{12} \mathrm{C}^{11} \mathrm{O}^{13}\right)$ \\
\hline 662 & 649 & 657 & $669(672)$ & 625 & 673 & $661-696$ & & & & $\Delta\left(\mathrm{O}^{12} \mathrm{C}^{11} \mathrm{O}^{13}\right)$ \\
\hline \multirow[t]{3}{*}{598} & & 583 & 596 & 604 & 585 & $593-595$ & 594 & 593 & $593-595$ & $\Gamma(\mathrm{CCC})_{\text {ring }} ; \delta\left(\mathrm{C}^{11} \mathrm{O}^{13} \mathrm{D}\right)$ \\
\hline & & & 584 & 563 & 584 & $575-586$ & 584 & 587 & $575-558$ & $\Gamma(\mathrm{CCC})_{\text {ring }}$ \\
\hline & & & $578(576)$ & 558 & 564 & $566-574$ & 575 & 558 & $565-570$ & $\Delta(\mathrm{CCC})_{\text {chain }}$ \\
\hline 581 & 578 & 581 & $562(565)$ & 543 & 554 & $525-538$ & 560 & 533 & $523-537$ & $\Delta(\mathrm{CCC})_{\text {ring }}$ \\
\hline \multirow[t]{2}{*}{539} & 560 & 545 & & & & & & & & $\Delta\left(\mathrm{C}^{9} \mathrm{C}^{10} \mathrm{C}^{11}\right)+\Delta\left(\mathrm{O}^{12} \mathrm{C}^{11} \mathrm{O}^{13}\right)$ \\
\hline & & & 528 & 543 & 527 & $512-517$ & & & $512-517$ & $\Delta\left(\mathrm{C}^{5} \mathrm{O}^{8} \mathrm{C}^{17}\right)+\Delta\left(\mathrm{C}^{10} \mathrm{C}^{11} \mathrm{O}^{13}\right)$ \\
\hline 532 & 521 & 527 & $508(503)$ & 515 & 510 & $494-503$ & & & $491-494$ & $\Delta\left(\mathrm{C}^{10} \mathrm{C}^{11} \mathrm{O}^{12}\right)+\Delta\left(\mathrm{C}^{3} \mathrm{C}^{9} \mathrm{C}^{10}\right)$ \\
\hline 466 & 471 & 470 & 501 & 489 & 488 & $721-730$ & 497 & 489 & $721-735$ & $\gamma\left(\mathrm{O}^{7} \mathrm{H}\right)$ \\
\hline 453 & 449 & 445 & $440(446)$ & 450 & 450 & $442-443$ & 438 & 446 & $442-443$ & $\begin{array}{l}\gamma\left(\mathbf{C}^{1} \mathrm{H}\right)+\gamma\left(\mathbf{C}^{4} \mathrm{H}\right)+\gamma\left(\mathrm{O}^{7} \mathrm{H}\right) \\
\gamma\left(\mathrm{O}^{13} \mathrm{D}\right)\end{array}$ \\
\hline 444 & & & & & & & & & & \\
\hline 374 & 395 & 397 & 393 & 398 & 399 & $395-397$ & 393 & 395 & $395-397$ & $\tau\left(\mathbf{C}^{3}-\mathrm{C}^{9}\right)$ \\
\hline 366 & & & 379 & 363 & 380 & $374-392$ & & & & $\Delta\left(\mathrm{C}^{5} \mathrm{O}^{8} \mathrm{C}^{17}\right)$ \\
\hline$\sim 330$ & & 320 & 335 & & 311 & $258-277$ & & & & $\nu\left(\mathrm{O}^{13}-\mathrm{H}^{24} \cdots \mathrm{O}^{12}\right)$ \\
\hline$\sim 330$ & & 314 & 315 & & & $327-351$ & & & & $\nu\left(\mathrm{O}^{7}-\mathrm{H}^{18} \cdots \mathrm{O}^{8}\right)$ \\
\hline & & & 290 & 281 & 282 & $284-294$ & 293 & 281 & $284-291$ & $\tau\left(\mathrm{CH}_{3}\right)$ \\
\hline 272 & 278 & 272 & & & & & & & & $\Delta\left(\mathrm{C}^{4} \mathrm{C}^{3} \mathrm{C}^{9}\right)+\Delta\left(\mathrm{C}^{9} \mathrm{C}^{10} \mathrm{C}^{11}\right)$ \\
\hline 258 & 257 & 251 & 259 & & 256 & $248-277$ & 260 & & & $\Delta\left(\mathrm{C}^{9} \mathrm{C}^{10} \mathrm{C}^{11}\right)$ \\
\hline 240 & 225 & 233 & 244 & & 226 & $246-247$ & 245 & & & $\gamma\left(\mathrm{O}^{8} \mathrm{H}\right) ; \tau\left(\mathrm{CH}_{3}\right)$ \\
\hline & & & 235 & 225 & 225 & $233-240$ & 235 & 225 & $239-247$ & $\tau\left(\mathrm{CH}_{3}\right)$ \\
\hline & & & 207 & & 222 & $195-197$ & 206 & & $194-197$ & $\nu\left(\mathrm{O}^{7}-\mathrm{H}^{18} \cdots \mathrm{O}^{8}\right)+\Delta\left(\mathrm{C}^{5} \mathrm{O}^{8} \mathrm{C}^{17}\right)$ \\
\hline 193 & 195 & 196 & & & & & & & & $\tau\left(C^{3}-C^{9}\right)$ \\
\hline 166 & & 165 & 191 & & 217 & $156-181$ & & & & $\nu\left(\mathrm{O}^{13}-\mathrm{H}^{24} \cdots \mathrm{O}^{12}\right)$ \\
\hline & & & 181 & 187 & 188 & $183-186$ & 181 & 187 & $183-186$ & $\tau\left(\mathrm{CH}_{3}\right)$ \\
\hline & & & 173 & & 171 & 176 & & & & External libration \\
\hline 146 & & 156 & 146 & & 156 & 146 & 146 & & & External libration \\
\hline 123 & & 131 & 129 & & & & 128 & & & External libration \\
\hline & & & 110 & & 113 & 115 & 110 & & & External libration \\
\hline$\sim 97$ & & 92 & $90(92)$ & & 92 & 95 & 89 & & & External libration \\
\hline 80 & & 78 & 80 & 80 & 81 & 76 & 82 & 80 & 82 & $\begin{array}{l}\text { External libration; } \\
\tau\left(\mathrm{C}^{5} \mathrm{O}^{8}\right)\end{array}$ \\
\hline
\end{tabular}


Table 1 (continued)

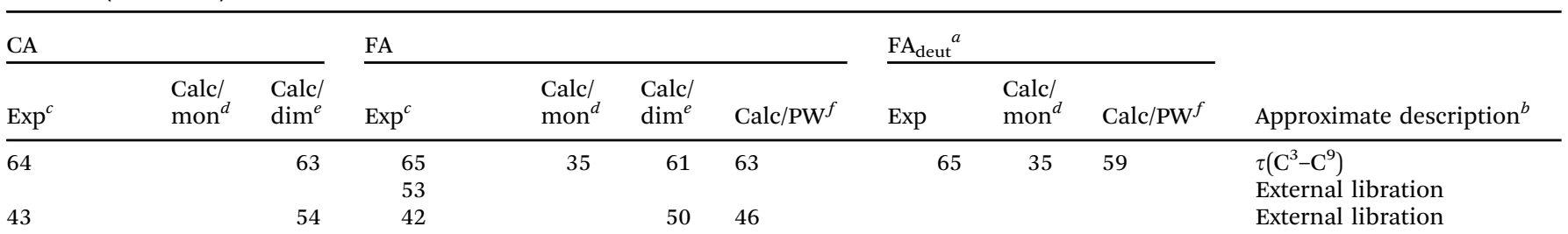

${ }^{a}$ Deuterated at $\mathrm{O}^{13} \cdot{ }^{b}$ Atoms are numbered according to Fig. $1 ; \nu$ - stretching, $\delta$ - in-plane deformation, $r$ - rocking, $\gamma$ - out-of-plane deformation, $\Delta$ - in-plane deformation of skeleton atoms, $\Gamma$ - out-of-plane deformation of skeleton atoms, $\tau$ - torsion; $s$ and as stand for symmetric and antisymmetric, while ip and op represent in-phase and out-of-phase modes. ${ }^{c}$ Raman experimental data in parentheses. ${ }^{26}{ }^{d}$ For the isolated molecule (monomer), at the B3LYP/6-31G $\mathrm{G}^{* *}$ level, wavenumbers above $550 \mathrm{~cm}^{-1}$ are scaled according to ref. $43 .{ }^{e}$ For the top-to-top centrosymmetric dimer, at the B3LYP/6-31G** level, wavenumbers above $500 \mathrm{~cm}^{-1}$ are scaled according to ref. $43 .{ }^{f}$ For the solid, at the PBE/PWSCF level.

obtained at the same level of theory. Frequencies above $500 \mathrm{~cm}^{-1}$ were scaled by $0.9614^{43}$ before comparing them with the experimental data, in order to correct for the anharmonicity of the normal modes of vibration. The theoretical INS transition intensities were obtained from the calculated normal mode eigenvectors of the quantum mechanical calculations, and the spectra simulated using the dedicated aCLIMAX program. ${ }^{29}$ This program accommodates the impact of the external modes of extended molecular solids through the choice of a suitable value for $\alpha_{i}$ (eqn (1)) - in the program this is the 'A-external' parameter and was chosen as $0.035 \AA$.

For the solid state, plane-wave expansions, as implemented in the PWSCF code from the Quantum Espresso package, ${ }^{44}$ were used, based on DFT methods within the generalized gradientcorrected PBE functional. ${ }^{45}$ The pseudopotentials employed were of the Vanderbilt ultrasoft type. ${ }^{46}$ A cutoff energy of 35 Ry and a Monkhorst-Pack grid ${ }^{47}$ of $3 \times 3 \times 3$ were found to be sufficient to attain convergence. For ferulic and cinnamic acids, the atomic coordinates were fully optimized using the published crystal structures $^{48,49}$ as a starting point.

\section{Results and discussion}

The compounds investigated here possess characteristic structural motifs that contribute to their biological activity: (i) the presence of electron-donating substituents in the aromatic ring (hydroxyl and/or methoxyl); (ii) the carboxylic moiety with an adjacent unsaturated $\mathrm{C}=\mathrm{C}$ double bond, providing additional sites of attack for free radicals and also acting as an anchor to the lipid bilayer.

The most stable geometries for the phenolic acids under study were previously determined to display an s-cis conformation of the carboxylic group $\left(\left(\mathrm{H}^{24} \mathrm{O}^{13} \mathrm{C}^{11} \mathrm{O}^{12}\right)=0^{\circ}\right.$, Fig. 1), along with a trans orientation of the aromatic ring relative to the terminal carboxylate $\left(\left(\mathrm{C}^{3} \mathrm{C}^{9} \mathrm{C}^{10} \mathrm{C}^{11}\right)=180^{\circ}\right){ }^{6,21,24,27}$ All energy minima have a planar geometry that favours the stabilizing effect of the $\pi$-electron delocalization between the ring and the $\mathrm{C}^{9} \mathrm{C}^{10}$ and $\mathrm{C}^{11} \mathrm{O}^{12}$ double bonds. A typical structural feature of cinnamic acids and their derivatives is the partial double bond character of $\left(\mathrm{C}^{3}-\mathrm{C}^{9}\right)$ and $\left(\mathrm{C}^{10}-\mathrm{C}^{11}\right)\left(d=145-147 \mathrm{pm}^{21,24,27}\right)$, reflecting the effective electron delocalization between the aromatic ring, the unsaturated pendant chain and the carboxylic moiety. In fact, the Wiberg indexes calculated for this series of compounds vary within the range 1.11-1.13 and 1.05-1.06 for the $\left(\mathrm{C}^{3}-\mathrm{C}^{9}\right)$ and $\left(\mathrm{C}^{10}-\mathrm{C}^{11}\right)$ bonds, respectively. Moreover, for the dihydroxylated caffeic acid, an identical orientation of the phenyl $\mathrm{OH}$ substituents (coplanar with the ring) was found to be strongly favoured, since it minimizes steric repulsions and enables the formation of highly stabilising medium strength intramolecular $(\mathrm{O}) \mathrm{H} \cdots \mathrm{O}$ interactions $\left(d_{(\mathrm{O} \cdots \mathrm{H})}=211 \mathrm{pm},{ }^{24}\right.$ 2nd-order $\mathrm{Lp}\left(\mathrm{O}^{12}\right) \rightarrow$ $\sigma^{*} \mathrm{O}_{10} \mathrm{H}_{11}$ stabilising energy $=11.3 \mathrm{~kJ} \mathrm{~mol}^{-1}$ ).

Fig. 2 shows the optimized solid state structure (at the PBE/ PWSCF level) of ferulic acid, evidencing the ( $\mathrm{H} \cdots \mathrm{O})$ intermolecular interactions $(d=153 \mathrm{pm})$ responsible for the compound's structure and properties (e.g. antioxidant activity).

The experimental INS spectra of cinnamic and monohydroxylated cinnamic acids ( $p$ - and $m$-coumaric) are shown in Fig. 3, while the corresponding data for the disubstituted caffeic and ferulic acids are depicted in Fig. 4. Good quality spectra were obtained, allowing us to identify the main vibrational bands for these molecules, in the light of the calculated INS spectra at the $\mathrm{B} 3 \mathrm{LYP} / 6-31 \mathrm{G}^{* *}$ level, for both the isolated molecule and the dimeric species (top-to-top dimers, Fig. 5).

As reflected by the spectra represented in Fig. 3, ring hydroxylation and the location of the $\mathrm{OH}$ substituent relative to the alkyl unsaturated carbon chain were found to have a marked effect on the vibrational profile of this kind of systems, due to a change in their electronic delocalisation as well as in their intermolecular arrangement (dimeric pattern) in the solid.

As a consequence, a different Davydov splitting pattern was observed for the monohydroxylated $p$ - and $m$-coumaric acids at $158 / 163,218 / 224,341 / 356,414 / 419$ and $575 / 588 \mathrm{~cm}^{-1}$ for the former, and at $335 / 342,577 / 588,852 / 864$ and $967 / 980 \mathrm{~cm}^{-1}$ for the latter (Fig. 3). This type of band splitting is due to the occurrence of distinct arrangements in the unit cell, leading to two crystallographically and energetically inequivalent species. This doubling of the unit cell was previously observed for $n$-alkanes ${ }^{50}$ and linear polyamines. ${ }^{51}$ Furthermore, the presence of several molecules in a crystal (or a packed solid state) generates an external force field, which is responsible for new vibrational modes - the so-called external modes (usually below ca. $200 \mathrm{~cm}^{-1}$ (ref. 50 and 52)). These are easily identified in the INS spectra presently obtained (Fig. 3 and 4).

The main peaks reflecting $\mathrm{H}$-bond interactions, which play an essential role in the conformational equilibrium of the phenolic derivatives under study, were unequivocally identified 
Table 2 Main experimental and calculated INS wavenumbers $\left(\mathrm{cm}^{-1}\right)$ for cinnamic, and $p$ - and $m$-coumaric acids

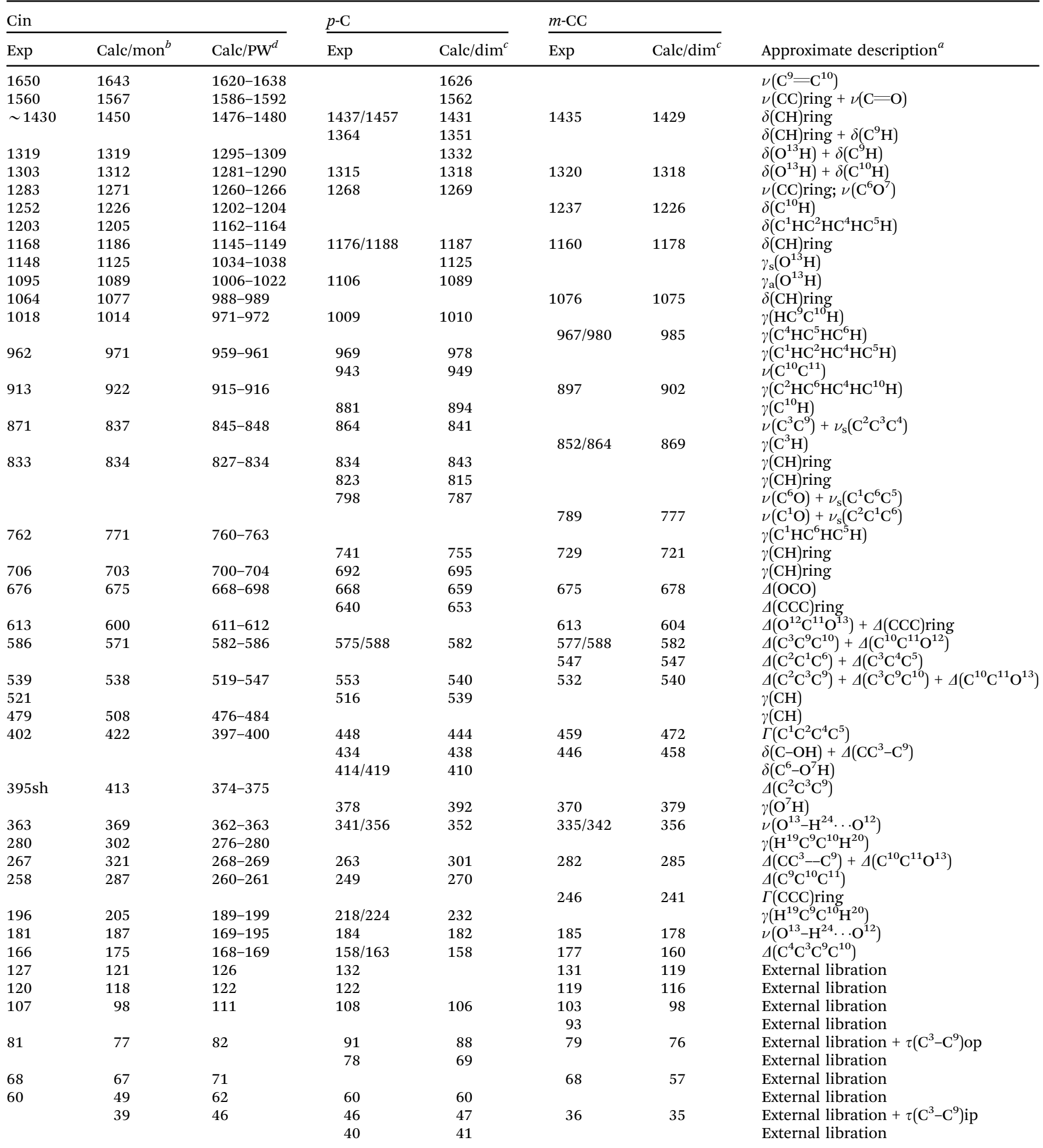

${ }^{a}$ Atoms are numbered according to Fig. $1 ; \nu$ - stretching, $\delta$ - in-plane deformation, $r$ - rocking, $\gamma$ - out-of-plane deformation, $\Delta$ - in-plane deformation of skeleton atoms, $\Gamma$ - out-of-plane deformation of skeleton atoms; $s$ and $a$ stand for symmetric and antisymmetric. ${ }^{b}$ For the isolated molecule (monomer), at the B3LYP/6-31G ${ }^{* *}$ level, wavenumbers above $500 \mathrm{~cm}^{-1}$ are scaled according to ref. $43 .^{c}$ For the top-to-top centrosymmetric dimer, at the B3LYP/6-31G** level, wavenumbers above $500 \mathrm{~cm}^{-1}$ are scaled according to ref. $43 .{ }^{d}$ For the solid, at the PBE/PWSCF level.

in their INS spectra, namely the features due to the $((\mathrm{H}) \mathrm{O} \cdots \mathrm{H})$ stretching modes associated with the top-to-top $\left(\mathrm{O}^{13}\right) \mathrm{H}^{24} \cdots \mathrm{O}^{12}$ close contacts within the dimeric species present in the solid: ${ }^{22,27}$ at ca. 180 and $350 \mathrm{~cm}^{-1}$ (Fig. 3, 4 and 6, Tables 1 and 2). Additionally, the occurrence of these centrosymmetric dimers formed through two intermolecular $\mathrm{H}$-bonds between carboxylic 
groups $\left(d_{(\mathrm{H} \cdots \mathrm{O})}\right.$ equal to $165 \mathrm{pm}$ in the dimer (Fig. 5) and $153 \mathrm{pm}$ in the solid (Fig. 2)) leads to an expected shift of the calculated carbonyl stretching vibration to lower wavenumbers as compared to the monomer (isolated molecule): e.g. 1701 vs. $1742 \mathrm{~cm}^{-1}$, for ferulic acid, the former being in good accordance with the observed value at $1698 \mathrm{~cm}^{-1}$ (Table 1). Moreover, the presence of intramolecular H-bonds between the hydroxyl hydrogen in the para position and the meta oxygen atom (from the hydroxyl in caffeic and the methoxyl in ferulic acids) was also detected.

Since the scattering by deuterium is roughly two orders of magnitude weaker than that by hydrogen, specific deuteration of the compounds is a very useful approach for an accurate assignment of the vibrational modes due to H-bonding interactions. For ferulic acid, spectra were acquired for both the hydrogenated solid and the O-deuterated molecule at the carboxylic moiety $\left(\mathrm{O}^{13} \mathrm{D}^{24}\right.$ for $\mathrm{O}^{13} \mathrm{H}^{24}$ substitution, Fig. 1), leading to the unequivocal assignment of the vibrations associated with the $\left(\mathrm{O}^{13} \mathrm{H} \cdots \mathrm{O}^{12}\right)$ intermolecular close contacts (in the low wavenumber region) (Table 1, Fig. 4(B) and (C)). As expected, deuteration alters the vibrational pattern according to two main factors: (i) increase in the mass of the oscillators involving the deuterated carboxylic group; and (ii) disruption of the $\left(\mathrm{O}^{13}\right) \mathrm{H}^{24} \cdots \mathrm{O}^{12}(=\mathrm{C})$ interactions (responsible for the formation of centrosymmetric dimeric species in the condensed phase, Fig. 2 and 5), giving rise to significantly weaker $\left(\mathrm{O}^{13}\right) \mathrm{D}^{24} \cdots \mathrm{O}^{12}(=\mathrm{C})$ close contacts. ${ }^{53}$ Accordingly, the INS pattern of non-deuterated versus deuterated ferulic acid reflects these changes (Table 1, Fig. 4), particularly for: (i) the signals ascribed to $\gamma\left(\mathrm{O}^{13} \mathrm{H}\right)$, $\delta\left(\mathrm{O}^{13} \mathrm{H}\right)$ and $\nu\left(\mathrm{C}^{11}-\mathrm{O}^{13}\right)$; and (ii) the characteristic $\delta\left(\mathrm{O}^{13} \mathrm{H} \cdots \mathrm{O}^{12}\right)$ feature (at $192 \mathrm{~cm}^{-1}$ ), which disappears by $\mathrm{O}^{13}$-deuteration (Fig. 4). In addition, the calculated wavenumbers for the stretching mode of the carboxylic OH group - 2151/2208 vs. $2926 / 3025 \mathrm{~cm}^{-1}$, respectively (Table 1 ) - as expected reproduce the $\mathrm{O}^{13}-\mathrm{D}^{24}$ for $\mathrm{O}^{13}-\mathrm{H}^{24}$ substitution.

When comparing the solid state experimental neutron scattering data with the results yielded by the calculations, a better agreement is found for the INS spectra predicted for the dimers (Table 1, Fig. 6 and 7) relative to the monomers, since they represent condensed phase conditions much more closely than isolated molecule approaches, by taking into account the intermolecular close contacts within the solid. Regarding ferulic acid, for instance, the bands assigned to lattice modes at 114 and below $53 \mathrm{~cm}^{-1}$ are clearly seen in the calculated spectrum of the dimer, whereas they are absent in the monomer (Fig. 7). Actually, applying PW approaches to the representation of the experimental data (e.g. for ferulic acid, Fig. 7) further increases the agreement between simulation and experience. However, note that the $\mathrm{PW}$ bands associated with the $\mathrm{O}^{13}-\mathrm{H}$ stretch of the $\left(\mathrm{O}^{13}\right) \mathrm{H}^{24} \cdots \mathrm{O}^{12}$ hydrogen bond, as well as the $\gamma\left(\mathrm{O}^{7} \mathrm{H}\right)$, are significantly shifted with respect to the dimer bands computed at the B3LYP/6-31G** level (Table 1). The lower $\mathrm{O}^{13}-\mathrm{H}$ stretching frequencies at the $\mathrm{PW}$ level are essentially due to the different density functionals employed, which yield a shorter hydrogen bond for the PBE functional and PW (153 pm) than for B3LYP/6-31G** (165 pm). For further comparison, we have calculated the dimer frequencies at the $\mathrm{PBE} / 6-31 \mathrm{G}^{* *}$ level,

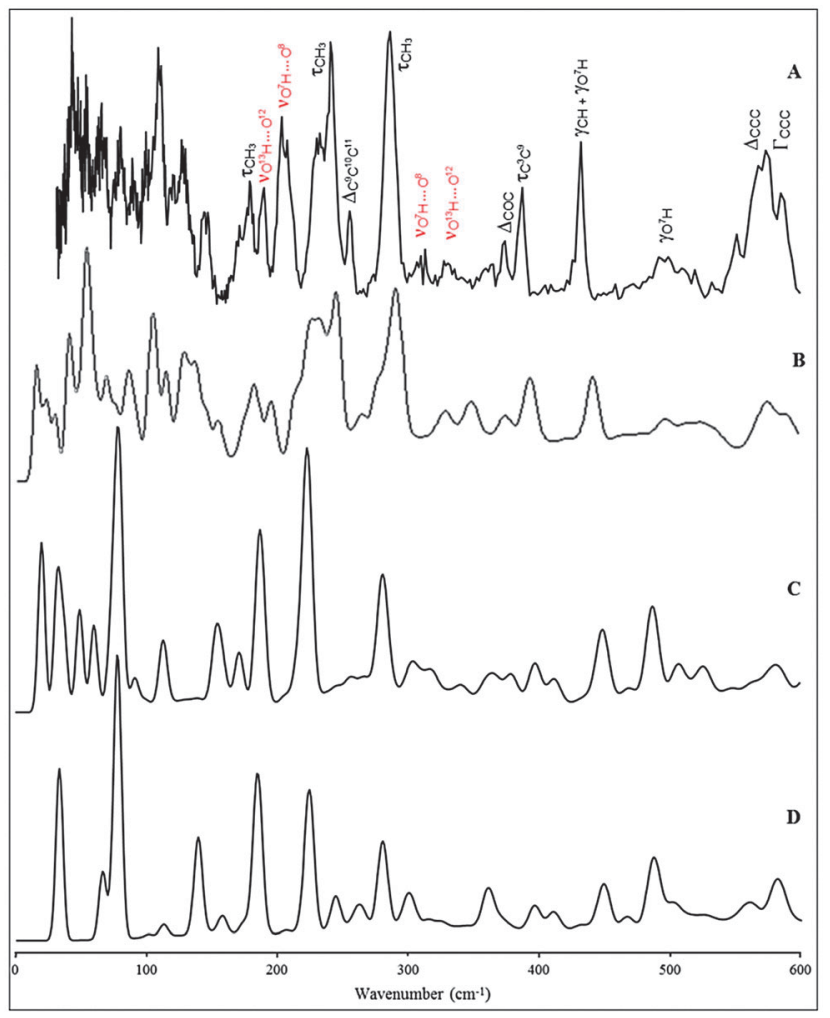

Fig. 7 INS spectra $\left(0-600 \mathrm{~cm}^{-1}\right)$ for ferulic acid: experimental (A); calculated for the solid state, at the PBE/PWSCF level (B); calculated for the isolated molecule (C) and the top-to-top centrosymmetric dimer (D), at the B3LYP/6-31G** level. (The atoms are numbered according to Fig. 1.)

i.e. with the same density functional used in the PW calculations. The results thus obtained evidence an $\mathrm{H}$-bond distance of $155 \mathrm{pm}$ and $\nu\left(\mathrm{O}^{13} \mathrm{H}\right)$ frequencies equal to 2485 and $2662 \mathrm{~cm}^{-1}$, with corresponding $\nu\left(\mathrm{O}^{13} \mathrm{D}\right)$ frequencies of 1868 and $1937 \mathrm{~cm}^{-1}$. In both cases, these values compare well with those obtained at the PW level, which are much lower than the B3LYP/6-31G** wavenumbers: the shorter hydrogen bonds cause the $\mathrm{O}^{13} \mathrm{H}$ distance to elongate, thus decreasing its stretching frequency. On the other hand, the much larger $\gamma\left(\mathrm{O}^{7} \mathrm{H}\right)$ frequency at the PW level is due to the solid-state structure, namely, to the fact that the hydrogen of the hydroxyl $\mathrm{O}^{7}-\mathrm{H}$ bond of one molecule is involved in an $\mathrm{H}$-bond with the oxygen of the $\mathrm{C}^{11}-\mathrm{O}^{12}$ carbonyl of another molecule (Fig. 2). This close contact is absent in the isolated monomer and dimer representations.

\section{Conclusions}

Naturally occurring bioactive phenolic and polyphenolic compounds are important components of the human diet, due to their antioxidant capacity that decreases oxidative stressinduced cell damage associated with severe pathologies such as cardiovascular or neurodegenerative disorders and cancer. Moreover, in view of their wide range of beneficial properties, they are promising new leads for the development of improved pharmaceuticals, namely chemopreventive agents. The antioxidant 
capacity of this type of compounds, which rules their overall biological activity, occurs through the formation of the corresponding phenoxyl radicals, directly related to their phenolic $\mathrm{OH}$ groups, and is strongly dependent on their conformational behaviour and hydrogen-bonding motif. Hence, the knowledge of these preferences is essential for a better understanding and prediction of the antioxidant ability of these phytochemicals.

The results shown here evidence that the structural stability and conformational behaviour of these systems relies on the balance between intra- and intermolecular hydrogen-type interactions, which are very accurately probed by inelastic neutron scattering techniques coupled with ab initio calculations. Access to the low frequency region of the spectrum unveiled the dependence of the vibrational modes occurring in this energy range relative to the molecular packing in the condensed phase, namely through the detection of characteristic Davydov splittings and of vibrational modes assigned to intermolecular H-bonds.

\section{Acknowledgements}

The authors are thankful for financial support from the Portuguese Foundation for Science and Technology - PEst-OE/QUI/UI0070/ 2014. The INS work was supported by the European Commission under the 7th Framework Programme through the Key Action: Strengthening the European Research Area, Research Infrastructures. Contract no. CP-CSA_INFRA-2008-1.1.1 Number 226507NMI3. The STFC Rutherford Appleton Laboratory is thanked for access to neutron beam facilities.

\section{Notes and references}

1 C. A. Gomes, M. T. Girão da Cruz, J. L. Andrade, N. Milhazes, F. Borges and M. P. M. Marques, J. Med. Chem., 2003, 46, 5395-5401.

2 P. Fresco, F. Borges, C. Diniz and M. P. M. Marques, Med. Res. Rev., 2006, 26, 747-766.

3 N. F. L. Machado and M. P. M. Marques, Curr. Bioact. Compd., 2010, 6, 76-89.

4 W. Russell and G. Duthie, Proc. Nutr. Soc., 2011, 70, 389-396.

5 T. Kaneko, N. Baba and M. Matsuo, Cytotechnology, 2001, 35, 43-55.

6 S. M. Fiuza, C. Gomes, L. J. Teixeira, M. T. Girão da Cruz, M. N. D. S. Cordeiro, N. Milhazes, F. Borges and M. P. M. Marques, Bioorg. Med. Chem., 2004, 12, 3581-3589.

7 M. A. Soobrattee, V. S. Neergheen, A. Luximon-Ramma, O. I. Aruoma and T. Bahorun, Mutat. Res., Fundam. Mol. Mech. Mutagen., 2005, 579, 200-213.

8 B. H. Wang and J. P. Ou-Yang, Cardiovasc. Drug Rev., 2005, 23, 161-172.

9 M. P. M. Marques, F. Borges, J. Sousa, R. Calheiros, J. Garrido, A. Gaspar, F. Antunes, C. Diniz and P. Fresco, Lett. Drug Des. Discovery, 2006, 3, 316-320.

10 A. M. Boudet, Phytochemicals, 2007, 68, 2722-2735.
11 G. T. Wondrak, C. M. Cabello, N. F. Villeneuve, S. Zhang, S. Ley, Y. J. Li, Z. Sun and D. D. Zhang, Free Radicals Biol. Med., 2008, 45, 385-395.

12 I. Kubo, Q. Chen and K. Nihei, Food Chem., 2003, 81, 241-247.

13 P. J. Ferguson, E. Kurowska, D. J. Feeman, A. F. Chambers and D. J. Koropatnick, J. Nutr., 2004, 134, 1529-1535.

14 T. Nagaoka, A. H. Banskota, Y. Tezuka, I. Saiki and S. Kadota, Bioorg. Med. Chem., 2002, 10, 3351-3359.

15 M. Fitó, M. I. Covas, R. M. Lamuela-Raventos, J. Vila, L. Torrents, C. de la Torre and J. Marrugat, Lipids, 2000, 35, 633-638.

16 J. B. Sousa, R. Calheiros, V. Rio, F. Borges and M. P. M. Marques, THEOCHEM, 2006, 783, 122-135.

17 M. Cárdenas, M. Marder, V. C. Blank and L. P. Roguin, Bioorg. Med. Chem., 2006, 14, 2966-2971.

18 H. C. Kuo, W. H. Kuo, Y. J. Lee, W. L. Lin, F. P. Chou and T. H. Tseng, Cancer Lett., 2006, 234, 199-208.

19 C. Manach, A. Scalbert, C. Morand, C. Rémésy and L. Jiménez, Am. J. Clin. Nutr., 2004, 79, 727-747.

20 P. Mattila, J. Hellstrom and R. Torronen, J. Agric. Food Chem., 2006, 54, 7193-7199.

21 N. F. L. Machado, R. Calheiros, S. M. Fiuza, F. Borges, A. Gaspar, J. Garrido and M. P. M. Marques, J. Mol. Model., 2007, 13, 865-877.

22 N. F. L. Machado, R. Calheiros, A. Gaspar, J. Garrido, F. Borges and M. P. M. Marques, J. Raman Spectrosc., 2009, 40, 80-85.

23 M. Ge, H. Zhao, W. Wang, Z. Zhang, X. Yu and W. Li, J. Biol. Phys., 2006, 32, 403-412.

24 E. van Besien and M. P. M. Marques, THEOCHEM, 2003, 625, 265-275.

25 S. M. Fiuza, E. van Besien, N. Milhazes, F. Borges and M. P. M. Marques, THEOCHEM, 2004, 693, 103-118.

26 R. Calheiros, N. F. L. Machado, S. M. Fiuza, A. Gaspar, J. Garrido, N. Milhazes, F. Borges and M. P. M. Marques, J. Raman Spectrosc., 2008, 39, 95-107.

27 R. Calheiros, F. Borges and M. P. M. Marques, THEOCHEM, 2009, 913, 146-156.

28 N. F. L. Machado, C. Ruano, J. L. Castro, M. P. M. Marques and J. C. Otero, Phys. Chem. Chem. Phys., 2011, 13, 1012-1018.

29 A. J. Ramirez-Cuesta, Comput. Phys. Commun., 2004, 157, 226-238.

30 R. Vuilleumier and D. Borgis, Nat. Chem., 2012, 4, 432-433. 31 http://www.isis.stfc.ac.uk/instruments/tosca/tosca4715. html, 11 February, 2013, United Kingdom.

32 M. J. Frisch, G. W. Trucks, H. B. Schlegel, G. E. Scuseria, M. A. Robb, J. R. Cheeseman, J. A. Montgomery Jr., T. Vreven, K. N. Kudin, J. C. Burant, J. M. Millam, S. S. Iyengar, J. Tomasi, V. Barone, B. Mennucci, M. Cossi, G. Scalmani, N. Rega, G. A. Petersson, H. Nakatsuji, M. Hada, M. Ehara, K. Toyota, R. Fukuda, J. Hasegawa, M. Ishida, T. Nakajima, Y. Honda, O. Kitao, H. Nakai, M. Klene, X. Li, J. E. Knox, H. P. Hratchian, J. B. Cross, C. Adamo, J. Jaramillo, R. Gomperts, R. E. Stratmann, O. Yazyev, A. J. Austin, R. Cammi, C. Pomelli, J. W. Ochterski, P. Y. Ayala, K. Morokuma, G. A. Voth, 
P. Salvador, J. J. Dannenberg, V. G. Zakrzewski, S. Dapprich, A. D. Daniels, M. C. Strain, O. Farkas, D. K. Malick, A. D. Rabuck, K. Raghavachari, J. B. Foresman, J. V. Ortiz, Q. Cui, A. G. Baboul, S. Clifford, J. Cioslowski, B. B. Stefanov, G. Liu, A. Liashenko, P. Piskorz, I. Komaromi, R. L. Martin, D. J. Fox, T. Keith, M. A. Al-Laham, C. Y. Peng, A. Nanayakkara, M. Challacombe, P. M. W. Gill, B. Johnson, W. Chen, M. W. Wong, C. Gonzalez and J. A. Pople, Gaussian 03 (Revision B.04), Gaussian Inc., Pittsburgh, PA, USA, 2003.

33 C. Lee, W. Yang and R. G. Parr, Phys. Rev. B: Condens. Matter Mater. Phys., 1988, 37, 785-789.

34 B. Miehlich, A. Savin, H. Stoll and H. Preuss, Chem. Phys. Lett., 1989, 157, 200-206.

35 A. D. Becke, Phys. Rev. A: At., Mol., Opt. Phys., 1988, 38, 3098-3100.

36 A. D. Becke, J. Chem. Phys., 1993, 98, 1372-1377.

37 G. A. Petersson, A. Bennett, T. G. Tensfeldt, M. A. Allaham, W. A. Shirley and J. Mantzaris, J. Chem. Phys., 1988, 89, 2193-2218.

38 C. Peng, P. Y. Ayala, H. B. Schlegel and M. J. Frisch, J. Comput. Chem., 1996, 17, 49-56.

39 A. E. Reed, R. B. Weinstock and F. Weinhold, J. Chem. Phys., 1985, 83, 735-746.

40 A. E. Reed and F. Weinhold, J. Chem. Phys., 1985, 83, 1736-1740.

41 A. E. Reed, L. A. Curtiss and F. Weinhold, Chem. Rev., 1988, 88, 899-926.

42 E. D. Glendening, A. E. Reed, J. E. Carpenter and F. Weinhold, NBO Version 3.1, Guassian 03 User's Reference Manual, Gaussian, Inc., Pittsburgh, PA, 2003.
43 J. P. Merrick, D. Moran and L. Radom, J. Phys. Chem. A, 2007, 111, 11683-11700.

44 P. Giannozzi, S. Baroni, N. Bonini, M. Calandra, R. Car, C. Cavazzoni, D. Ceresoli, G. L. Chiarotti, M. Cococcioni, I. Dabo, A. Dal Corso, S. de Gironcoli, S. Fabris, G. Fratesi, R. Gebauer, U. Gerstmann, C. Gougoussis, A. Kokalj, M. Lazzeri, L. Martin-Samos, N. Marzari, F. Mauri, R. Mazzarello, S. Paolini, A. Pasquarello, L. Paulatto, C. Sbraccia, S. Scandolo, G. Sclauzero, A. P. Seitsonen, A. Smogunov, P. Umari and R. M. Wentzcovitch, J. Phys.: Condens. Matter, 2009, 21, 395502.

45 J. P. Perdew, K. Burke and M. Ernzerhof, Phys. Rev. Lett., 1996, 77, 3865-3868.

46 D. Vanderbilt, Phys. Rev. B: Condens. Matter Mater. Phys., 1990, 41, 7892-7895.

47 H. J. Monkhorst and J. D. Pack, Phys. Rev. B: Condens. Matter Mater. Phys., 1976, 13, 5188-5192.

48 M. Nethaji, V. Pattabhi and G. R. Desiraju, Acta Crystallogr., Sect. C: Cryst. Struct. Commun., 1988, 44, 275-277.

49 D. A. Wierda, T. L. Feng and A. R. Barron, Acta Crystallogr., Sect. C: Cryst. Struct. Commun., 1989, 45, 338-339.

50 J. Tomkinson, S. F. Parker, D. A. Braden and B. S. Hudson, Phys. Chem. Chem. Phys., 2002, 4, 716-721.

51 M. P. M. Marques, L. A. E. Batista de Carvalho and J. Tomkinson, J. Phys. Chem. A, 2002, 106, 2473-2482.

52 L. A. E. Batista de Carvalho, M. P. M. Marques and J. Tomkinson, J. Phys. Chem. A, 2006, 110, 12947-12954.

53 A. M. Amado and P. J. A. Ribeiro-Claro, J. Chem. Soc., Faraday Trans., 1997, 93, 2387-2390. 